
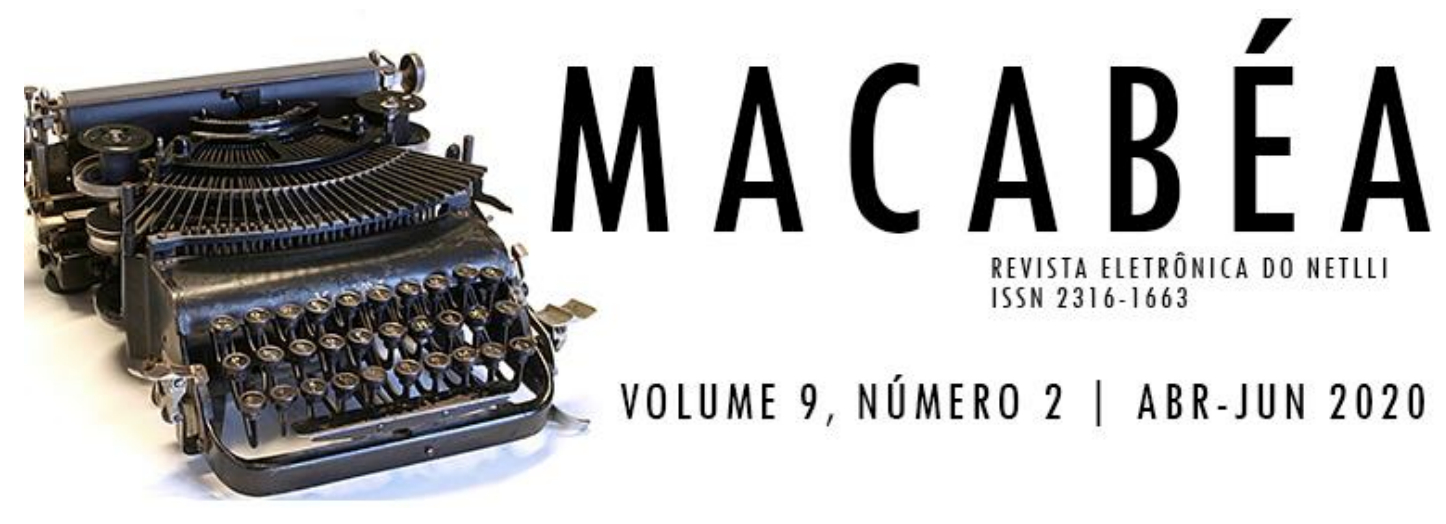

VOLUME 9, NÚMERO 2 | ABR-JUN 2020

\title{
EM NOME DOS PAIS: A NARRATIVA DE FILIAÇÃO NA LITERATURA BRASILEIRA CONTEMPORÂNEA
}

\section{ON BEHALF OF PARENTS: THE AFFILIATION NARRATIVE IN CONTEMPORARY BRAZILIAN LITERATURE}

\author{
RESUMO | INDEXAÇÃO | TEXTO | REFERÊNCIAS | CITAR ESTE ARTIGO | 0 AUTOR \\ RECEBIDO EM 29/12/2019 • APROVADO EM 08/03/2020
}

\footnotetext{
Abstract

From a socio-historical-cultural context identified as the era of catastrophes, there is a recurrent form of life writing that discusses the historical trauma in an intrinsic relationship with the memory transmitted by the intergenerational bond. The affiliation narrative, as conceptualized by Dominique Viart, is a phenomenon of the literary making of the present, observable in different cultures in the globalized world. We seek, in this article, to observe the possible relationships between life writing, the historical trauma and post-memory, highlighting in the work Em nome dos pais by Matheus Leitão, the traces of the affiliation narrative postulated by Viart. We denote, in general lines, that the affiliation narrative, as perceptible in this work, delineates a contemporary form of literary making committed to using self-reference to break the silence, the interdictions and, in a widely transitive perception of literature, narrate what is of the order of the unspeakable.
} 


\section{Resumo}

A partir de um contexto sócio-histórico-cultural identificado como era das catástrofes, se faz recorrente uma forma de escrita de si que tematiza 0 trauma histórico numa intrínseca relação com a memória transmitida pelo laço intergeracional. A narrativa de filiação, como conceituado por Dominique Viart, é um fenômeno do fazer literário dos dias presentes, observável em diferentes culturas no mundo globalizado. Buscamos, nesse espaço de discussão, observar as possíveis relações entre as escritas de si, 0 trauma histórico e a memória transgeracional destacando na obra Em nome dos pais de Matheus Leitão os traços da narrativa de filiação postulados por Viart. Denotamos, em linhas gerais, que a narrativa de filiação, como perceptível na referida obra, delineia uma forma contemporânea de fazer literário comprometido em usar a autorreferência para romper 0 silêncio, as interdições e, numa percep̧̧ão amplamente transitiva de literatura, narrar aquilo que é da ordem do inenarrável.

\section{Entradas para indexação}

KEYWORDS: Affiliation narrative. life writing. historical trauma. post-memory. contemporary literature.

PALAVRAS-CHAVE: Narrativa de filiação. escritas de si. trauma histórico. pós-memória. literatura contemporânea.

\section{Texto integral}

\section{Introdução}

A narrativa constitui forma de expressão humana que dá materialidade às experiências dos sujeitos na dimensão linguageira. Dessa maneira, não assume apenas papel de instrumento que dá margem ao dado vivencial do ser humano, as histórias de vida acontecem narrativamente, Em diferentes aspectos, contornos e possibilidades elaborativas, a narração permite que a vida humana adquira sentido e significação, sendo narrativamente experimentável pelo próprio sujeito e por aqueles que o cercam.

O narrar, nessa perspectiva, é ato imbuído de certa relação com aquilo que se viveu ou se crê ter vivido. Esse elo com a vivência toma corporeidade em distintas formas a partir de suas finalidades e condições específicas, tendo dicções que lhe serão características a partir de variados elementos que figuram no arranjo enunciativo e influenciam a narratividade em curso, seja por sua relação dialógica com o contexto interno à linguagem em uso ou mesmo externo a ela.

No amplo espectro das formas narrativas, nossa discussão circunda o território literário das narrativas íntimas, demarcado, em nossa perspectiva, pelo espaço biográfico, conceito proposto por Arfuch (2010) como um horizonte contemporâneo onde coabitam as mais diversas formas narrativas que tematizam intencionalmente a subjetividade, sua constituição como tal e sua história individual. $\mathrm{O}$ conceito sinaliza a evidência de uma constante ocorrência das mais 
diversas variedades de narrativas íntimas indo desde as formas mais tradicionais (biografias, autobiografias, diários, memórias) a formas que se ramificam e se hibridizam na atmosfera de fragmentalidade e transitoriedade que dimensiona as relações humanas em ares contemporâneos.

Nesse ritmo, sob a chave de um olhar que se debruça sobre as narrativas de vida pelo prisma da contemporaneidade, intencionamos problematizar a relação entre elementos tais quais a memória, a experiência, a história individual e a história coletiva. Com especificidade, o foco de nossa discussão recai sobre a obra Em nome dos pais (2017), escrita pelo jornalista brasileiro Matheus Leitão, em um enredo no qual a história do Brasil, no período de aproximadamente 20 anos que compreende a Ditadura Militar, se interpola de maneira inextricável com a história de vida de seus pais e, em um olhar transgeracional, com a sua própria.

Temos em vista, na referida obra, características que se aproximam de uma forma de narratividade observada nos dias contemporâneos em diferentes culturas, mais especificamente na França, de onde parte, por meio das pesquisas de Dominique Viart, o conceito recit de filiation, no Brasil adotado como narrativa de filiação (NORONHA, 2014). A proposição de Viart e a maneira como ele identifica as características desse recorrente fenômeno nos dias atuais, nos permite destacar como a interrelação entre os elementos discutidos no presente texto se elaboram na tessitura da obra Em nome dos pais.

\section{Um olhar sobre o contemporâneo}

Como propõe Bakhtin (2017), a literatura está intimamente relacionada com o contexto externo que a circunda, suas relações com o contexto extralinguístico influenciam diretamente seu relativo acabamento. A partir desse fato podemos apontar um olhar para a obra literária em sua relação transitiva com o presente de sua enunciação. Nesse sentido, o primeiro aspecto que queremos desenvolver em nossa proposta é a percepção sobre a contemporaneidade, momento em que, de forma recorrente, observa-se em diferentes culturas a presença de obras que se alinham às características das narrativas de filiação como proposto por Viart e Vercier (2008).

Aos olhos de teóricos da filosofia e sociologia que versam sobre o sujeito e suas relações com o mundo no âmbito do contemporâneo por diferentes horizontes de contemplação, podemos suscitar, de início, alguns posicionamentos comuns que convergem no sentido do que afirma Andreas Huyssen (1984). 0 pensador sinaliza as profundas transformações culturais nas sociedades ocidentais na passagem da modernidade para o que convem chamar pós-modernidade, dentre elas fica ressaltado o forte questionamento de certas posturas e ideais racionalistas que por muito exerceram forte influência nas bases das sociedades ocidentais no arco da modernidade.

Em uma direção semelhante, Giorgio Agamben (2002) nota que dentre estas transformações sensíveis no entorno do modus vivendi contemporâneo se destaca o câmbio na relação do sujeito com a sua vivência e a sensação de tempo. No 
pensamento de Agamben, nos dias contemporâneos existiria uma força intempestiva que tem modificado a forma com que o sujeito olha para o presente tempo. Em seu olhar para sua presenticidade cabe certo movimento dialógico entre os valores da tradição e sua ressignificação, o que opera, dentre outras coisas, a gradativa corrosão e a pulverização das instâncias reguladoras e institucionalizadas socialmente.

O contemporâneo, como proposto por Giorgio Agamben, se relaciona, por esse olhar, diretamente com aquilo que é fruto da pequena temporalidade, da atualidade, do presente e do passado recente. Fica proposta uma reflexão sobre o contemporâneo que toma por ênfase as incertezas e relatividades que o momento atual flexiona na vida do sujeito contemporâneo. Em suas palavras:

Contemporâneo é aquele que mantém fixo o olhar no seu tempo, para nele perceber não as luzes, mas o escuro. Todos os tempos são, para quem deles experimenta contemporaneidade, obscuros. Contemporâneo é, justamente, aquele que sabe ver essa obscuridade, que é capaz de escrever mergulhando a pena nas trevas do presente. [...] perceber esse escuro não é uma forma de inércia ou de passividade, mas implica uma atividade e uma habilidade particular que, no nosso caso, equivalem a neutralizar as luzes que provêm da época para descobrir as suas trevas, o seu escuro especial, que não é, no entanto, separável daquelas luzes. (AGAMBEN, 2012, p.63).

O sujeito contemporâneo é este que habita um espaço acampado em torno do constantemente inacabado, daquilo que não se caracteriza de maneira determinista, plenamente concluído e fechado, mas sim se configura através de processos, no vir-a-ser, sem desconsiderar, sobretudo, as luzes que o trouxeram até aquele ponto do caminho. A noção de sujeito, nesse prisma, não mais se estabelece por uma existência centrada, consciente e unívoca, uma identidade única e fechada em si mesma, no entanto, toma forma nesse ínterim uma visão de subjetividade espectral, em que múltiplos processos de identificação podem acontecer a um único indivíduo.

A essa relação de multiplicidade nos processos de subjetivação não podemos nos furtar de propor um diálogo com o que afirma Stuart Hall (2006, p.12-13) acerca da contundente fragmentação que as identidades, aparentemente conformadas em si mesmas, passam a sofrer nos dias pós-modernos. 0 estudioso aponta que: “0 próprio processo de identificação, através do qual nos projetamos em nossas identidades culturais, tornou-se mais provisório, variável e problemático", salientando que as identidades não se apresentam como uma porção fixa, pronta e acabada, marca de um eu coeso e coerente, mas se constroem a partir das demandas sociais e culturais no fluir histórico de cada grupo social específico. O sujeito se percebe como tal a partir de uma diversa malha de possibilidades de papeis identitários que vem a assumir de maneira processual a julgar pelo contexto em que se insere, podendo ser identitariamente constituído 
por papeis que não necessariamente se alinham de maneira harmônica a compor a relativa estabilidade que integra essa subjetividade.

Percebe-se nesse percurso que tradições e valores canônicos em diversas esferas da interação humana têm seus status ressemantizados. De forma concomitante, passa-se a observar, por exemplo, a pluralidade de formas de existir, a abrir espaço para um pensamento que não mais preconiza a homogeneização e opera a partir da consideração de uma maior amplitude de sentidos e de vozes, as quais por muito foram massificadas ou pormenorizadas em meio à constituição universalizadora da História das comunidades ocidentais.

Outras menções que em nosso percurso é relevante que sejam ressaltadas se relacionam ao hedonismo exacerbado que destaca Gilles Lipovetsky ao considerar o contemporâneo como um contexto de hipermodernidade. Em seu trabalho intitulado Os tempos hipermodernos (2004), publicado juntamente com Sebastien Charles, ficam demarcadas de maneira enfática algumas premissas quanto à configuração do sujeito contemporâneo, o homo oeconomicus, e da sociedade a qual este integra, em que, segundo Lipovetsky (2004, p.81):

\begin{abstract}
Coabitam duas tendências: a que acelera os ritmos tende à desencarnação dos prazeres; a outra, ao contrário, leva à estetização dos gozos, à felicidade dos sentidos, à busca da qualidade no agora. De um lado, um tempo comprimido, "eficiente", abstrato; de outro, um tempo de foco no qualitativo, nas volúpias corporais, na sensualização do instante. Assim é que a sociedade ultra-moderna se apresenta como uma cultura desunificada e paradoxal. Um acasalamento de contrários que só faz intensificar dois importantes princípios, ambos constitutivos da modernidade técnica e democrática: a conquista da eficiência e o ideal da felicidade terrena.
\end{abstract}

Qualquer pretensão por uma plena estabilidade ou homogeneidade em dias tomados por sensível transitoriedade e, vide Zygmunt Bauman (1998), liquidez nas relações sociais e atividades humanas, se faz sob o peso de certa recusa à fractalização que é característica da atmosfera social em que tem forma a vida no espaço contemporâneo. Nessa conjuntura discutida até este ponto, podemos identificar uma série de traços específicos quanto a esse período ao qual se convencionou chamar pós-modernidade. Dentre esses traços, destacamos o descentramento do sujeito, a corrosão do status das instâncias reguladoras do poder, a busca por uma satisfação dos prazeres do indivíduo, a fragmentação e transitoriedade na construção dos processos identitários, a sensualização do instante etc. Uma sociedade que se singulariza, sobretudo, pelas consequências e reflexos de catástrofes globais que afetam de maneira direta e indireta a vida local e promovem a rasura dos limites entre essas ambivalências.

Nomeadamente, podemos elencar uma série de eventos catastróficos que deixaram marcas profundas em várias gerações de diferentes comunidades culturais ao redor do globo nos dias atuais. Se observarmos bem, para além do nosso foco temporal na contemporaneidade, catástrofes de diferentes tipos são 
presentes no decorrer do relato histórico, no entanto, no horizonte contemporâneo a frequente presença desses eventos, a forma com que eles são representados e como repercutem dialogicamente nas relações sociais, são grandes peculiaridades desse período que, dentre muitas adjetivações com o prefixo "pós", é também chamado de pós-catástrofe.

A escrita da história, conforme discutem Viart e Vercier (2008), por sua vez, tomada pelas direções dessa forma de pensar pós-moderna, busca compreender aquilo que passou aos olhos dos sujeitos actantes, sem pretensões por totalidades ou demasiadas generalizações que apresentam versões homogeneizantes do acontecimento. 0 passado passa a ser visto de uma forma não linear, tendo sua cronologia tensionada, movida por leituras a contrapelo que propõem a revisão e reconstrução de experiências históricas considerando sua parcialidade e suas relações com o presente.

É nesse ponto de entrecruzamento entre o contexto contemporâneo que reflete diretamente sobre toda a produção estética do período e a problemática relação entre experiência e representação no tocante a esses eventos catastróficos que vemos abertura para discutir a configuração das narrativas de filiação. Esse tipo de expressão literária, identificado por Dominique Viart, surge no escopo das escritas de si como uma formação específica que apresenta, de maneira interpolada, a relação do sujeito com sua identidade heterogeneamente constituída em meio aos reflexos de eventos catastróficos. Um tipo de relato que dá lugar a uma voz subjetiva que atua como espaço para o diálogo entre um olhar para o outro e o mundo que transcende os contornos do eu.

\section{Trauma, legado e narrativas de filiação}

Pensando na baila das proposições de teóricos como Jean-François Lyotard e Saul Friedländer, Seligmann-Silva (2000) discute a aporia entre a impossibilidade de representação desses acontecimentos tão destrutivos que não conseguem ganhar conformidade nas dimensões do pensamento humano e, ao mesmo tempo, a necessidade concomitante de falar sobre essas feridas tão profundas que marcam, contemporaneamente, os processos identitários intergeracionais de vários sistemas culturais. 0 pesquisador desenvolve, então, a problemática em torno da representação desses eventos a partir de noções freudianas no campo da psicanálise, mobilizando conceitos como o sublime, o testemunho e o trauma. Levantando uma relação com a vivência traumática, com uma necessidade de compreender o passado que se projeta no presente e que tem consequências futuras, esse olhar intermedia questionamentos e posturas antagônicas que resvalam entre querer/não conseguir esquecer e dever/ não conseguir lembrar.

Fica proposta a reflexão de que no presente nos cabe lidar com os ecos desses eventos catastróficos, dessas feridas na memória que nos afetam, porém cujas raízes remontam a uma atualidade que não é diretamente a nossa. Nas palavras de Marianne Hirsch (2008), somos a segunda geração, a de descendentes 
de vítimas de eventos traumáticos que herdam memórias da geração precedente como se fossem de fato experiências também vividas por nós, estabelecendo uma conexão intrínseca com o passado que não nos foi experimentado, mas, sim, transmitido. Há nesse percurso uma relação com o trauma em nível histórico, uma fratura na memória coletiva de um grupo social que é entretecida discursivamente pelas experiências vividas em plano individual e pelos ecos dessas experiências sensíveis no plano comum.

Na linha do conceito de memória coletiva em Halbwachs (2013), a memória se constrói nessa dupla orientação, como um ato que se elabora no plano do indivíduo e subentende, necessariamente, sua inserção e partilha com determinado grupo de referência, localizado histórico-socio-culturalmente. A noção de Pierre Nora (1990, p.451) coaduna com a percepção de Halbwachs e percebe memória coletiva, em síntese, como: "a memória, ou o conjunto de memórias, mais ou menos conscientes de uma experiência vivida ou mitificada por uma comunidade, cuja identidade é parte integrante do sentimento do passado". Por essas lentes, o dado mnemônico é formado na relação intersubjetiva do sujeito com o meio social, num sentido em que podemos pensar a memória como resultante de um diálogo entre um ato que parte do plano individual e estabelece contato contínuo com os processos constitutivos de memória em horizonte coletivo.

No caso do que propõe Hirsch, essa relação social que de forma involuntária integra o exercício da memória é levada a outro patamar da vivência coletiva. Tratamos de um tipo de experiência que marca de forma incomensurável o curso de uma vida, fratura na memória que ecoa em tom insistente no quotidiano das vítimas primárias, trazendo reverberações indeléveis àqueles que com eles convivem e coabitam, por exemplo, a cena familiar. A história de Art Spiegelman (2009) autobiograficamente registrada em Maus pela dicção das histórias em quadrinhos é um desses exemplos na literatura contemporânea usados por Hirsch para trabalhar seu conceito de pós-memória. Para a pesquisadora, essa noção:

[...] é distinguida da memória por uma distância geracional, e da história por uma profunda conexão pessoal. A pós-memória é uma forma poderosa e muito particular de memória, precisamente, porque sua relação com objetos e com fontes não é mediada por lembranças, mas, sim, por um investimento imaginário e pela criação. [...] A pós-memória caracteriza a experiência daqueles que cresceram imersos em narrativas que precederam seus nascimentos, como se a história pessoal tivesse sido esvaziada pelas histórias de vida das gerações anteriores, moldadas por experiências traumatizantes (HIRSCH, 2002, p.22, tradução nossa).

Essa segunda geração, sem qualquer escolha, herda um legado traumático transferido pelos laços de filiação na convivência com as testemunhas diretas de eventos dessa natureza. 0 uso do prefixo pós na conceituação de Hirsch efetiva justamente esse sentido de afastamento temporal, essa vivência internalizada de 
forma tardia ante o acontecimento originário. São sujeitos que, por essa distância espaço-temporal mantida com o acontecimento, se relacionam com suas memórias do acontecido através de um misto de processos que recai sobre a ficcionalização ou imaginação dos ocorridos com a soma de registros históricos e outros dados de memória coletiva.

Em Maus, por exemplo, vemos, por grande parte da narração, o que parece ser o empréstimo do olhar do filho para vozeificar, em tom biográfico, as experiências traumatizantes do pai com o período do Holocausto, talvez uma tentativa de restituir aquilo que marcou sua história de vida. No entanto, numa chave de leitura distinta, podemos perceber que esse relato de fundo aparentemente biográfico, acaba se configurando como uma forma de lidar com as feridas na história e configuração identitária do próprio filho, evidenciando como aquela memória traumática da qual o pai e a mãe são testemunhas diretas, também encontra no filho seus efeitos e reflexos de maneira particular.

De forma contundente, em Régine Robin (2016) podemos ver, acerca desse tipo específico de relato em que a memória é transgeracional, a distância do sujeito em relação ao real efetivar um indício de que a representação dessa testemunha indireta não pode traduzir, em face das interdições e lacunas da transmissão, o que ocorreu em determinada experiência traumática. Todavia, Robin pontua, em relação ao relato de sobrevivente em Maus, algo que nos é extremamente relevante na compreensão das narrativas de filiação:

\begin{abstract}
A história do pai em Auschwitz e a do filho incapaz de continuar seu livro se entrecruzam constantemente. Sua depressão está ligada aos acontecimentos que tem experimentado, vivido, e também àqueles que ele não viveu, em Auschwitz, a partir da experiência indizível de seus pais. Na realidade, a máscara (em todas as sessões de análise Art usa uma máscara) vai levá-lo a compreender, graças à narração que ele empreende, que a relação que mantém com o Holocausto não é a sua (daí a máscara), mas, sim, a de seu pai e, que por isso, ele precisa encontrar seu próprio modo de conexão com o Holocausto, sua própria história, sua própria narrativa.[...] Art, o filho de um sobrevivente, que herdou sua culpa de sobrevivente, que herdou o trauma do pai, tem, contudo, uma outra história. (ROBIN, 2016, p.319-320).
\end{abstract}

O legado traumático passado ao herdeiro pode ser percebido por este pela chave da restituição, uma tentativa de reestabelecer a memória esquecida daquilo que uma vez foi. É também, por certo, tributar algo a alguém, devolver ou reparar aquilo que um dia foi perdido. Essa, possivelmente, é a razão inicial e (aparentemente) consciente com que Art Spiegelman começa o empreendimento de Maus, tributar a seus pais ou a si mesmo algo que necessita ser reposto ou reconstituído. Nesse ensejo, é que Spiegelman busca no testemunho de Vladek, quanto ao Holocausto, as pistas para narrar aquilo que poderia ser sua restituição.

Contudo, ainda sob o signo da falta, vemos que a descoberta do filho é a de que a história do pai não é necessariamente a sua, de que a forma com que seu pai 
lidou com as memórias daquele evento não poderia ser a mesma com que ele lidaria. A sua história de sobrevivente existe, no entanto, sob uma vertente distinta daquela de seu pai e cuja representação comporta, talvez, outras incursões. Foi ao ceder o seu espaço de si para observar aquilo que era necessário ser contado acerca do mundo e do lugar do outro, que Spiegelman observou lacunas e questionamentos na constituição daquilo que compete ao $e u$.

Na linha das considerações em torno de relatos como o de Maus, é que Dominique Viart, observa no contexto da sociedade francesa a frequência e caraterísticas desse tipo de relato que elabora sobre a linha da autorreferencialidade e do trauma histórico, relações entre a história individual e a história coletiva. Propondo reflexões que conectam o ético e o estético, o pesquisador francês apresenta discussão em torno do contemporâneo e como nesse período repercute a representação do trauma histórico, enfatizando ser:

[...] notável que um número de escritores, certos deles sem qualquer vínculo pessoal ou familiar com o genocídio, se achem exigidos a se confrontar a ele, ao ponto de uma revista recentemente poder falar de uma 'geração' definida por esse fenômeno. Eu vejo aí o sinal literário de um atendimento, pelo conjunto do corpo social, a um acontecimento cuja significação excede as experiências particulares - e que não se resolve pelo 'dever de memória'. Mas como se apropriar disso sobre o qual pesa um tal interdito?(VIART, 2011, p.26, tradução nossa).

É comum, então, que o evento traumático figure como conteúdo de distintas formas de expressão literária na cena contemporânea, uma constatação de como esses tipos de acontecimento são tão profundos que transcendem as dimensões da experiência individual e tem ecos consideráveis no plano coletivo. Cabe destacar, no entanto, a pergunta na citação anterior, em que nos inquirimos acerca do escrúpulo com que aquilo que segue na ordem do indizível, toma forma no seio da representação literária. Acreditamos em tom alusivo ao que depreende Viart na sequência desse questionamento que: "Há sem dúvida um certo escândalo em se instalar assim na vida e na morte de um outro. Mas o escândalo seria também deixar essa vida e essa morte se dissolver no silêncio que as cerca." (VIART, 2011,p.28, tradução nossa). Na obra literária que discutiremos posteriormente em nosso texto, essa obrigação com a enunciação daquilo que não pode ser esquecido fica externada por Matheus Leitão na linha de um novo legado transgeracional:

Apesar de ser um não nascido quando tudo isso se passou, o reencontro com o passado ocorreu num presente em que tenho filhos, aos quais quero contar a história da geração dos seus avós. Escrevo para que meus filhos não se esqueçam da luta dos meus pais. Tento ser esse elo no tempo para que ela nunca se perca. (LEITÃo, 2017, p.15, tradução nossa). 
Dessa forma é perceptível a maneira transitiva com que a literatura exerce seu papel na contemporaneidade. Sobretudo, esse tipo de literatura aqui reiterado por Viart que se singulariza por combinar a ficcionalização do vivido em favor de uma função figurante, "necessariamente subjetiva, e assumida como tal. Ela não compõe personagens, não constrói histórias. Ela ensaia figuras [...]”. (VIART, 2011, p.28, tradução nossa). Essa maneira de fazer literatura, inscrita na contemporaneidade, tem o necessário dever de rasgar o véu que encobre e vela aquilo que precisa ser dito, sem anistias, sem demolições, sem substituições ou apagamentos. Em suma, variadas formas da narratividade contemporânea têm por característica o que fica emblemático na conseguinte colocação de Viart:

'O inimaginável precisa ser imaginado. Ali onde nenhuma imagem pode se formar, é preciso formar uma imagem', escreveu Rykner. Tal é, talvez, o desafio que a literatura hoje se faz: figurar o infigurável.[...] Não se trata tanto de propor narrativas ali onde elas faltam terrivelmente, mas de procurar como dizer hoje essa herança coletiva que o saber positivo não é suficiente para carregar - e como prova do quê o texto projeta. A escritura ali inventa uma outra maneira de ser. Essa suspeita que a modernidade lhe lega, mais do que dela se desviar, se faz o escrúpulo de sua relação com a História e com o mundo.(VIART, 2011,p.28, tradução nossa).

São formas que combinam dois tipos de tendências contemporâneas observadas por Françoise Simonet-Tenant (2007) especificamente na autoficção, mas que podem ser lateralizadas para observar outras formas de escritas de si. Primeiramente, a miniaturização que se desenvolve por uma predileção em narrar a vida a partir de eventos singulares que marcam determinado sujeito, ao invés de uma pretensa ambição totalizante característica da autobiografia tradicional. 0 foco recai sobre a vida em sua fragmentação, uma notória alusão ao pensamento pós-moderno que postula o sujeito em seu descentramento e sua identidade fragmentada. Outra tendência destacada corriqueiramente por diferentes teóricos é a hibridização, a forma com que essas formas narrativas se elaboram na constituição de gêneros tradicionais em uma configuração intercalada, a saber, o romance, a autobiografia, a biografia etc.

As narrativas de filiação, ao caminhar desse escopo e sob a forma com que desenvolve Viart, se singularizam por alguns aspectos específicos muitos dos quais já pontuamos de maneira pulverizada ao longo do texto. Demonstramos a seguir de forma mais detalhada como estes traços constitutivos funcionam no acabamento da obra Em nome dos pais (2017), de Matheus Leitão. Buscamos, a partir de nossas considerações quanto à referida obra, fomentar reflexões acerca de como a memória transgeracional é representada na literatura brasileira contemporânea.

\section{A narrativa de filiação em Em nome dos pais}


Em nome dos pais é uma obra de cunho autobiográfico que desenvolve, sob o diálogo entre as narrativas de vida e a escrita jornalística, o entrecruzamento entre experiências marcantes da história de vida dos jornalistas Míriam Leitão e Marcelo Netto e momentos da história coletiva brasileira, datados no período conturbado e obscuro da Ditadura Militar brasileira. Matheus, segundo filho do casal, depois do irmão Vladimir, o qual Míriam carregava em sua barriga no momento em que era submetida à tortura, empreende em sua obra um verdadeiro trabalho de investigação da história do país, que parte inicialmente de seu desejo por reparar e tributar a seus pais aquilo que os anos de repressão da ditadura militar os havia imputado. Além disso, na obra de Leitão nos fica claro, desde os primeiros momentos de sua narração, que seu ensejo por trazer luz sobre os lacunados fatos que lhe foram sussurrados desde a infância, não somente recai sobre o ato de fazer justiça à história de seus pais ou a da coletividade brasileira, mas recai sobre narrar a sua própria história, junto à herança traumática que lhe foi legada.

Narrado em três partes, o texto é composto por relatos de suas buscas por documentos e testemunhas que pudessem esclarecer como seus pais haviam sido delatados, presos e torturados no período de repressão política em questão. 0 jornalista e pesquisador agrega a sua obra não só a materialidade escrita como também intercala, entre as páginas de seus relatos, registros documentais, fotos, desenhos, trechos de canções, grafites, entre outros tipos de registros que são resultados de sua investigação do passado de seus pais em meio a história do país. Esse apelo verbo-visual, acima de outras coisas, leva para outra dimensão os relatos de Leitão, em que o leitor sente-se convidado e questionado a aproximar-se das razões factuais que emanam de sua narração.

Percebemos de início que as tendências de hibridização e miniaturização pontuadas por Simonet-Tenant (2007) são contempláveis nessa leitura preliminar da obra, em que vemos uma narração de eventos fragmentários e singulares na trajetória individual das personagens e a intercalação de distintas formas de representação no arranjo dessa narrativa. Um grande ponto comum na narrativa de filiação destacado por Viart e Vercier (2008), indiscutivelmente sensível na obra de Leitão, é a herança traumática transmitida pelos vínculos da filiação em um diálogo intergeracional, a qual motiva e dita as condições do empreendimento narrativo.

O foco na história do outro como um necessário percurso para encontrar a si é outro elemento que podemos destacar na leitura horizontal de narrativas de filiação como as obras dos franceses Annie Ernaux, Claude Simon e Pierre Michon, contempladas por Viart e Vercier (2008) em seus trabalhos e, também, como já foi destacado, em Maus de Art Spiegelman (2009). Esse outro para quem o sujeito cede sua elocução é um determinado ancestral de quem o herdeiro recebe sua herança, cuja história de vida figura como chave para que este herdeiro possa compreender seu papel em relação ao legado que também lhe constitui. 0 foco , nesse encaminhar, é uma leitura em que o herdeiro investiga, então, a sua relação com o passado que lhe foi compartilhado, sua ascendência. 
A partir do título "Em nome dos pais", fica subentendido que a história a ser figurada no âmbito da narrativa de Leitão é a história de seus pais, de forma específica, entendemos que a obra é uma dedicatória, que serve a uma lógica da restituição presente nesse tipo de texto. A obra é dedicada por Leitão não somente a seus pais, mas a toda a geração deles, àqueles que sofreram de maneira direta com as perdas provocadas pela série de acontecimentos situados no Brasil entre 1964 e 1985. Em sua apresentação o autor coloca:

O fio condutor compreende o meu entendimento da prisão e da tortura sofridas por meus pais, a angústia que isso me provocou, a procura por documentos oficiais e a investigação, até encontrar aquele que os delatou aos militares. Narro também a visita que fiz a um dos locais em que meu pai esteve preso, na mesma época que minha mãe, e a árdua peregrinação atrás dos torturadores, a mais sofrida e fatigante. Por isso este livro está em primeira pessoa. É o relato da minha procura. (LEITÃO, 2017, p.13).

Pensamos ser possível afirmar, em especial no que condiz às últimas sentenças da citação anterior, que o espaço que Matheus Leitão cede em sua investigação do passado de seus pais se confunde com a sua própria procura, uma procura de si. 0 empreendimento narrativo em torno dessa filiação e de suas relações entre testemunhas e herdeiros é um lócus em que figura uma busca pela compreensão de fragmentos de si, necessária a esses sujeitos que cresceram sob o peso de interditos, silêncios, choros abafados, tentativas de esquecer para seguir em frente. É uma jornada que parece ser inevitável, em nosso ver, quando observamos que a própria história do nome, lugar onde se articulam sujeito e identidade, elo entre gerações, é envolto por relações reiterativas do trauma, como no caso de Matheus Leitão. Ainda pré-adolescente, em sua primeira conversa aberta com o pai, após ouvir sussurros de palavras como "perseguição, prisão e porão", o autor relata a história de seu nome:

- Seu codinome, então, será Mateus - comunicou o dirigente ao meu pai, fazendo o seu batismo comunista.

Mateus? O nome de guerra do meu pai, o nome pelo qual ele se tornaria conhecido em sua luta seria Mateus? O meu nome? Enganchou. A história fisgou o meu interesse como um peixe que morde a isca e não consegue se livrar do anzol, bem enfiado, por dentro, até o lado de fora de sua boca. Eu poderia lutar, me debater, mover-me para um lado ou para outro. Mas ela sempre estaria lá, a história. (LEITÃO, 2017, p.21, grifos do autor).

Como coloca o jornalista, esse passado atravessa sua história pessoal de maneira inseparável, lhe sendo praticamente impossível recusar ou negar a profunda relação que os acontecimentos traumáticos daquele período significativamente trazem para sua história de vida. Como ele mesmo afirma, a ditadura militar brasileira influenciou grandemente seu viver desde antes de seu nascimento e, no âmbito da presente narrativa, ele se vê parte incontestável desse 
legado, declarando ser: "arrastado por uma linha tênue, porém tensa, entre a minha própria história e a dos meus pais. Ou essa seria também a minha história de certa forma?" (LEITÃO, 2017, p.21).

Outra característica das narrativas de filiação levantada por Viart e Vercier (2008) lida com aspectos de ordem mais formal em relação à construção desse tipo de narrativa. Para os pesquisadores franceses:

O texto se acomoda mal ao modelo romanesco, e procura encontrar uma forma que lhe será própria, fora da tradicional trajetória autobiográfica [...]. Essa forma será justamente a da narrativa de filiação que lida com o romance pela ficção que por vezes é obrigada a construir e com a autobiografia pelas dimensões factual e íntima que são as suas, embora sem jamais se reabsorver nela. (VIART, VERCIER, 2008, p.81, tradução nossa).

Na narrativa de filiação o diálogo estabelecido com o discurso romanesco e o discurso autobiográfico são efetivados pela já mencionada característica que esta forma de narratividade tem de problematizar por meio da autorreferencialidade a relação entre a história individual e a história coletiva pelo viés da herança traumática. A ligação com a autobiografia se estabelece por uma conexão quanto aos elementos que garantem referencialidade e intimismo na perspectiva da narração dos acontecimentos da vida de uma determinada subjetividade. No que tange ao romance, a narrativa de filiação usa do ficcional para preencher as lacunas daquilo que ao herdeiro não foi possível experimentar ou que lhe foi interdito no processo de transmissão. Existe, portanto, uma ficcionalização de diversos momentos da narrativa que se empreendem por um exercício imaginativo cuja proposta é dar conta daquilo que o herdeiro não teve acesso no percurso de vida do ancestral.

Em Em nome dos pais, a presença da ficcionalização é sensível quando se trata especificamente do relato de episódios testemunhados pelos pais do autornarrador-personagem. Tal movimento narrativo é presente, nesse sentido, na narração de momentos que provavelmente foram a ele transmitidos no diálogo intergeracional ou por ele descobertos no processo de sua empreitada investigativa, como se trata de uma obra que relaciona o texto autobiográfico com a investigação jornalística Existe um momento de destaque na narração de Leitão em que a estratégia de ficcionalização em uma função figurante, como afirma Viart (2011), pode ser observada, momento este em que o autor descreve episódios de tortura sofridos por Míriam Leitão, sua mãe:

Tapas, cachorros ferozes, cobras em quartos escuros, assédio sexual contra minha mãe grávida, passeios noturnos sem saber pra onde, ameaças de estupro e morte...

- Eu posso te matar, sabia? - disse um militar de olhos azuis com o revólver apontado contra a cabeça da jovem Míriam, de dezenove anos.

- Sim, você pode - respondeu ela, mas não houve tiro. 
Aquela foi uma das cenas que ela guardou para sempre por que foi quando entendeu pela primeira vez - haveria outros momentos assim - que a vida na época estava por um fio. De pé, no corredor central do quartel onde ficou presa, Míriam aguardava para entrar em uma das salas de interrogatório. 0 oficial chegou, sacou a arma e, subitamente, colocou o cano em sua fronte. Diante do que ele havia dito, ela o olhou. Gravou os olhos azuis e a frieza daquele homem - nunca identificado. E se sentiu muito só. Descobriu de forma profunda que se ele apertasse o gatilho bastava depois desaparecer com o corpo dela ou inventar a versão do "resistiu à prisão". Quando ela disse "sim, você pode", era isso mesmo que queria dizer. 0 militar tinha esse poder, porque numa ditadura é assim. Os dois sustentaram o olhar por um tempo indefinível. Ele abaixou a arma e saiu. (LEITÃO, 2017, p.23).

Observando a forma com que essa cena é desenvolvida, vemos que a narração empreendida por Leitão só é possível, em maior ou menor grau, a partir de sua ficcionalização em viés imaginativo, que toma por base o dado transmitido no laço intergeracional. Ficcionalizar o vivido, mesmo no que concerne a escrita da testemunha direta, é ação presente na atividade narrativa a julgar por suas distintas modalidades, ainda que minimamente. No caso da narrativa de filiação essa ficcionalização se torna indispensável ao investimento imaginativo que Viart (2011) denota nesses textos, consequência, em nosso ver, da relação intergeracional do sujeito com essas memórias, sua transmissão e interdições, que fazem com que o herdeiro recorra a esse instrumento para conectar as informações às quais este, de alguma forma, tem (ou não) acesso.

$\mathrm{Na}$ linha desses interditos, é sensível na constituição das narrativas de filiação, conforme Viart e Vercier (2008), um desenvolvimento temporal que não respeita necessariamente uma ordem cronológica e linear dos acontecimentos e que não pretende sua reconstituição. Conforme os estudiosos: "Ela é antes de tudo uma recolha [...]. Ela é, em seguida, pela força das coisas, uma investigação: nenhum narrador pode conhecer por si mesmo as partes de vida de que não foi testemunha. [...]. Â recolha se somam, assim, pesquisas e hipóteses." (VIART, VERCIER, 2008, p.81, tradução nossa).

No caso de Em nome dos pais, são essas interdições inicialmente no cenário da transmissão familiar e depois no âmbito das barreiras impostas pelo governo e pela figura do Exército brasileiro em suas diferentes instâncias e orgãos, especificamente, que parecem alimentar no autor-narrador-personagem a sede por investigar a história de seus pais, do país e a sua própria. No caso das instâncias militares, Matheus Leitão faz menção específica à maneira com que os fatos são estranhamente (ou convenientemente) colocados de forma obscura e tendenciosa, repleto de obstáculos e limitações que o próprio Estado, na figura da força militar, faz uso para encobrir fatos e mesmo sustentar versões parciais quanto a esse período traumático da história nacional. Sobre essa questão da não linearidade temporal com que se desenvolve o relato, é destacável no texto de Leitão a seguinte afirmação: 
Este relato parece desorganizado no tempo. Mas foi assim mesmo que essas lembranças me foram descritas. Eu colhia retalhos daqui e dali. Não havia retratos arrumados de forma linear, apenas histórias dos pais contadas a um filho curioso e perguntador. (LEITÃO, 2017, p.26)

No último aspecto das narrativas de filiação proposto por Viart e Vercier (2008) figura a questão ética no uso da linguagem, a qual para os autores se circunscreve a um universo familiar, não apenas por uma questão de fidelidade, mas também, como apresentam os autores a partir do que discute Annie Ernaux, "pela preocupação de não fazer arte com aquilo que não o é". (VIART, VERCIER, 2017, p.81, tradução nossa). Nesse ponto, podemos propor um diálogo com a pergunta anteriormente sugerida por Viart (2011) ao suscitar a questão ética e estética da qual esta forma de expressão literária contemporânea não pode fugir. Como trazer à tona essas vivências sobre as quais de fato reverberam variadas interdições? Ao mesmo tempo, essa necessidade de manter a linguagem mais conectada ao cenário familiar evoca justamente uma pretensão por não estetizar excessivamente algo cuja dicção não compete esse tipo de linguagem.

No âmbito da obra de Matheus Leitão, os usos de linguagem respeitam essa preocupação e são empregados de maneira pouco estetizada, sem muitas estilizações e outros efeitos estéticos. Uma linguagem que é essencialmente intimista, mas que não deixa de trabalhar no viés factual que recai sobre o tipo de narrativa que está sob nosso foco, sobretudo, quando temos em vista o teor jornalístico e, consequentemente, documental que a obra Em nome dos pais também apresenta.

\section{Considerações}

Como podemos destacar ao longo de nosso percurso, a narrativa de filiação é marca de uma visão de sujeito que considera, dentre outras condições perceptíveis no desenho do contexto contemporâneo, sua constituição identitária fragmentária e interpelada pelas consequências e ecos das várias catástrofes que assolaram o século XX e ainda se fazem presentes no XXI. A narrativa de filiação, nesse viés dá centralidade a temáticas salientes nos dias atuais, com especificidade à condição dos sujeitos que, por meio da memória transmitida em perspectiva intergeracional, creem lidar com a história de um ancestral, mas acabam descobrindo que, ao invés de unicamente tematizar a busca pelo olhar do outro, lhes compete considerar seus próprios lugares em meio aos reflexos desse legado que igualmente lhes constitui.

Na obra Em nome dos pais, de Matheus Leitão, percebemos uma vertente desse tipo de narratividade que apresenta por meio de uma linguagem singularmente elaborada, os eventos em torno das incursões de um filho a um passado que se faz próximo a ele principalmente pela transmissão dos pais. Incursão investigativa em que este passado que vem à superfície, traz consigo reflexos que lançam luzes sobre a história de uma família, sobre a história de um 
país e sobre a história de um sujeito que teve toda sua vida atravessada por um acontecimento que esteve sempre ali, porém em uma presença velada, silenciosa e delicada. Um trauma que marcou vidas de maneira tão profunda que a sua representação não pode ser feita sem que de alguma forma haja hesitações ou desconfortos seja na parte de quem enuncia, de quem é objeto da enunciação ou daquele a quem esse texto tem por receptor.

Nos contornos do presente tempo e na literatura que se desenha sob essas luzes, a consideração maior é a de que nos cabe quebrar o silêncio e ousar romper com o discurso hipostático e com as tabulas rasas. Aquilo que uma vez foi silenciado precisa ser ouvido por uma sociedade que não pode se calar ou esquecer-se de onde veio. Os instrumentos que causam opressão não podem ser usados outra vez sob a recusa das marcas que figuram de maneira exposta em nossa sociedade, em nosso dia-a-dia. Não podemos simplesmente passar por cima de determinados atos, mas podemos, sim, aceitar o passado e empreender, a partir das partes envolvidas, reconciliações com o momento em que tais eventos se fizeram uma vez cabíveis para que outros legados e heranças possam ser construídos.

\section{Referências}

AGAMBEN, Giorgio. 0 que é o contemporâneo? E outros ensaios. Chapecó: Argos, 2012.

AGAMBEN, Giorgio. Infância e história: destruição da experiência da história. Tradução de Henrique Burigo. Belo Horizonte. UFMG, 2002.

ARFUCH, Leonor. El espacio biográfico: Dilemas de la subjetividad contemporánea. Buenos Aires: Fondo de Cultura Económica, 2010.

BAKHTIN, Mikhail. Notas sobre literatura, cultura e ciências humanas. Trad. Paulo Bezerra. São Paulo: 34, 2017.

BAUMAN, Zygmunt. 0 mal-estar da pós-modernidade. Rio de Janeiro: Jorge Zahar, 1998.

HALBWACHS, Maurice. A memória coletiva. Tradução de Beatriz Sidou. $2^{a}$ ed. São Paulo: Centauro, 2013. 
HALL, Stuart. A identidade cultural na pós - modernidade. Tradução de Tomaz Tadeu da Silva, Guacira Lopes Louro. Ed.11 Rio de janeiro: DP\&A, 2006.

HIRSCH, Marianne. Family frames, photography, narrative and postmemory. Harvard University Press: Cambridge, Massachussets, 2002.

HIRSCH, Marianne. The generation of postmemory. Poetics Today. No 29:1. Spring. Ithaca, 2008, p. 103-128.

HUYSSEN, Andreas. Mapping the postmodern. New German Critique. No.33. Fall. Ithaca, 1984, p.5-52.

LEITÃO, Matheus. Em nome dos pais. Rio de Janeiro: Intrínseca, 2017.

LIPOVETSKY, Gilles; CHARLES, Sebastien. Os tempos hipermodernos. São Paulo: Barcarolla, 2004.

NORA, Pierre. Memória colectiva. In: LE GOFF, Jacques; CHARTIER, Roger; REVEL, Jacques (Orgs.). A história nova. Coimbra: Almedina, 1990.

NORONHA, Jovita M. G. Em nome do pai. Organon, v. 29, Porto Alegre, 2014. p. 113-134.

ROBIN, Régine. A memória saturada. Campinas: Editora da UNICAMP, 2016.

SELIGMANN-SILVA, Márcio et. ali. Catástrofe e representação. São Paulo: Escuta 2000.

SIMONET-TENANT, Françoise (org). Le Propre de l'écriture de soi. Paris: Téraèdre, 2007.

SPIEGELMAN, Art. Maus: a história de um sobrevivente. Tradução de Antônio de Macedo Soares. São Paulo: Companhia das Letras, 2009.

VIART, Dominique; VERCIER, Bruno. La littérature française au présent. Héritage, modernité, mutations. 2e édition augmentée. Paris: Boras, 2008. 
VIART, Dominique. Le scrupule du roman. Vacarme. No.54. Invers. Paris, 2011,p. 26-28.

\section{Para citar este artigo}

SANTOS, Y. A. B. Em nome dos pais: A narrativa de filiação na literatura brasileira contemporânea. Macabéa - Revista Eletrônica do Netlli, Crato, v. 9., n. 2., 2020, p. 33-50.

\section{Os Autores}

Yuri Andrei Batista Santos é doutorando no Programa de Pós-graduação em Filologia e Língua Portuguesa (PPGFLP/USP) como bolsista FAPESP. Possui mestrado em Letras pelo Programa de Pósgraduação em Letras: Linguagens e representações (PPGLLR/UESC). Também possui graduação em Letras com dupla habilitação em Língua Portuguesa e suas literaturas e Língua Inglesa e suas literaturas pela UESC. É pesquisador vinculado ao grupo de pesquisa DIÁLOGO-USP. Tem experiência no ensino de línguas estrangeiras (inglês/alemão) com certificação de nível $\mathrm{Cl}$ em inglês pela Universidade de Cambridge e em alemão de nível B2 pelo Instituto Goethe. Atua nas seguintes áreas: teoria dialógica do discurso, escritas de si, análise comparativa de discursos, estudos de tradução, ensino de línguas estrangeiras, ludoletramento. 